\title{
Variably male-biased sex ratio in a marine bird with females larger than males
}

\author{
Roxana Torres $\cdot$ Hugh Drummond
}

Published online: 29 June 2009

(C) Springer-Verlag 2009

\section{Erratum to: Oecologia (1999) 118:16-22 DOI 10.1007/s004420050698}

The authors wish to publish an Erratum to this article. Here is their statement:

Torres and Drummond (1999) tested predictions from sex ratio theory by assessing the effect of breeding conditions on progeny sex ratios of the blue-footed booby (Sula nebouxii); a species in which females are larger and roughly $32 \%$ heavier than males, thus presumably more costly to rear. Torres and Drummond (1999) concluded that (1) during 1989 there was a male biased sex ratio at hatching and at fledging, (2) during five subsequent reproductive seasons (years 1990-1995; 1992 was not included because no fledglings were produced in that El Nino year) fledgling sex ratios were male biased in 4 years and the bias towards males was greater when mean sea surface temperature was warmer and prey fish were presumably scarcer, (3) during two warm-water years (1994 and 1995) fledging sex ratios increased with hatching date, (4) there was no association between parents' reproductive experience (number of fledglings produced in the 11 preceding years) and progeny sex ratio in the 2 years analyzed; a cool-water year with relatively abundant food (1989), and a warm-water year with

The online version of the original article can be found under doi: $10.1007 / \mathrm{s} 004420050698$

R. Torres $(\bowtie) \cdot H$. Drummond

Instituto de Ecología,

Universidad Nacional Autónoma de México,

A.P. 70-275, México D.F. 04510, Mexico

e-mail:1rtorres@ servidor.unam.mx relatively scarce food (1994), and (5) there was no association between sex ratio and hatching sequence in broods of two and three chicks in 1989. We now report that conclusions 2-4 are unreliable. Due to an error by the first author during data preparation, non-random samples of fledglings from the years 1990-1995 were excluded from the analyses, and there is no reliable way of determining the sex of these fledglings.

The sex of blue-footed booby offspring can be determined by the length of the ulna at a mean age of 79 days, when the sexes have reached a non-overlapping bimodal asymptote (range 191-207 mm for males and 213-233 mm for females; Drummond et al. 1991). In Torres and Drummond (1999) the sex of all offspring included in the analyses was determined by ulna length. However, although chicks of 1989 were measured when plumage development was completed, at mean ages of 86 days for males and 92 days for females (Drummond et al. 1991), chicks of 1990-1995 were measured at age 70 days, when some of them had not reached their asymptotic size and their sex could not be determined by this method. From the total sample of 1,344 available broods (2,350 fledglings), Torres and Drummond (1999) excluded 193 broods (275 fledglings). These broods were excluded because at least one 70day-old fledgling had an ulna length between 208 and $212 \mathrm{~mm}$, intermediate between the ranges of the two sexes in Drummond et al. (1991). Females take longer than males to reach asymptotic ulna length (Drummond et al. 1991) and intermediates were more likely to be undersized females than oversized males, so the sample of excluded broods was probably female-biased. From the excluded sample with intermediate ulnas 68 could be later sexed by voice (Nelson 1978) when they returned to breed in the colony ( $n=16$ males and 52 females), however the sex of the 115 birds with intermediate ulnas that did not return to the 
colony cannot be determined. Thus, we retract conclusions 2-4 (Torres and Drummond 1999): that during the period 1990-1995 fledgling sex ratios were male biased in 4 years and the bias towards males increased with mean sea surface temperature; that during 2 warm-water years (1994 and 1995) fledging sex ratios increased with hatching date; and that there was no association between parents' reproductive experience and progeny sex ratio in 1994.

\section{References}

Drummond H, Osorno JL, Torres R, García-Chavelas C, Merchant H (1991) Sexual size dimorphism and sibling competition: implication for avian sex ratios. Am Nat 138:623-641

Nelson JB (1978) The Sulidae: gannets and boobies. Oxford University Press, London

Torres R, Drummond H (1999) Variably male-biased sex ratio in a marine bird with reversed size dimorphism. Oecologia 118:16-22 